\title{
The inverse care law re-examined: a global perspective
}

Richard Cookson (corresponding author), $\mathrm{PhD}$, Centre for Health Economics, University of York, York YO10 5DD, England, Email richard.cookson@york.ac.uk

Tim Doran, MD, Department of Health Sciences, University of York, York, England Miqdad Asaria, PhD, Department of Health Policy, London School of Economics, England Indrani Gupta, PhD, Health Policy Research Unit, Institute of Economic Growth, Delhi, India Fiorella Parra Mujica, MSc, Department of Health Sciences, University of York, York, England

\section{Summary}

An inverse care law persists in almost all low-income and middle-income countries, whereby socially disadvantaged people receive less, and lower-quality, health care despite having greater need. By contrast, a disproportionate care law persists in high-income countries, whereby socially disadvantaged people receive more health care, but of worse quality and insufficient quantity to meet their additional needs. Both laws are caused not only by financial barriers and fragmented health insurance systems but also by social inequalities in care seeking and co-investment as well as the costs and benefits of health care. Investing in more integrated universal health coverage and stronger primary care, delivered in proportion to need, can improve population health and reduce health inequality. However, trade-offs sometimes exist between health policy objectives. Health-care technologies, policies, and resourcing should be subjected to distributional analysis of their equity impacts, to ensure the health inequality reduction objective is kept in sight. 


\section{Introduction}

Tudor Hart coined the term "inverse care law" (ICL) 1 in 1971 to describe the double injustice that socially disadvantaged people not only tend to suffer more illness than socially advantaged people but also receive less health care. ${ }^{2-5}$ He also noted that social class inequalities in primary care delivery in the United Kingdom (UK) had been substantially reduced but not eliminated by the introduction of the universal, tax-funded National Health Service (NHS) in 1948..$^{5-7}$ The term has since been widely adopted to describe social inequalities or disparities in health care of all kinds, with similar discussions in other countries $^{8}$, and similar phrases have been applied to related phenomena, including the "inverse equity hypothesis" (where new health interventions are adopted earlier by advantaged populations, thereby initially increasing inequalities $)^{9,10}$ and the "inverse hazard law" (where health risks vary inversely with wealth and power). ${ }^{11}$ The original article has been cited by more than 3,500 academic publications, mostly by authors outside the UK, and the annual citation rate continues to rise in the context of exponential growth in the general academic literature on health care inequalities in the last two decades (see appendix A1).

Our aim in this article is to re-examine the nature, magnitude and causes of social inequality in health care delivery from a global perspective in the light of advances in scientific knowledge since 1971. Heterogenous reporting makes it hard to compare the magnitude of health care inequality between studies, and cross-country studies still tend to focus on inequality in health care utilisation rather than the quality of care ${ }^{12}$. However, we are able to make cross-country comparisons of the magnitude of inequality in health care utilisation among high-income countries and, separately, among low- and middle-income countries, and to summarise a substantial body of knowledge about the causes of health care inequality from country-specific studies.

Since 1971, limited global progress has been made in tackling the ICL. A "complete" ICL where health care use decreases with social disadvantage - persists in almost all low- and middle-income countries. A "disproportionate" ICL - where health care use increases with social disadvantage but not in proportion to need - persists even in upper-middle and highincome countries with integrated systems of universal health coverage. The "complete" ICL is largely driven by financial barriers to health care in unregulated health care markets, and countries with worse governance tend to have larger ICLs. These barriers, and the inequalities associated with them, are reduced under integrated systems of universal health care. However, social inequalities in health care quality and outcomes persist due to social inequalities in: i) the ability to seek health care (for example, by taking time off work, navigating complex systems and avoiding discrimination); ii) the ability to benefit from health care (for example, by investing time and resources in following treatment regimens); and iii) the costs of health care and the risks of poor outcomes (for example, due to multimorbidity and medical workforce shortages).

\section{The inverse care law re-formulated}

The ICL was originally formulated as follows:

"The availability of good medical care tends to vary inversely with the need for it in the population served. This inverse care law operates more completely where health care is more exposed to market forces, and less so where such exposure is reduced."1 
This memorable phrase, punning on inverse square laws from the natural sciences, is an effective communication device that captures imaginations and resonates with people's experiences. However, we need to reformulate the ICL in a narrower but more precise way to facilitate empirical investigation of its magnitude and causes from a global perspective.

First, the ICL is solely concerned with differences in health care and need related to social disadvantage (for example, area deprivation, income, social class, ethnicity, gender) and not differences unrelated to social disadvantage. The ICL predicts: i) a negative association between social disadvantage and health care use among people with the same level of need ("horizontal inequity" related to social disadvantage); and ii) a positive relationship between social disadvantage and health care need ("vertical inequity" related to social disadvantage). However, among people who share the same level of social disadvantage, the ICL does not necessarily predict that those who need more health care will receive less (i.e. vertical inequity unrelated to social disadvantage).

Second, we distinguish inequality in the quantity of health care resources (e.g. workforce, utilisation, expenditure per capita) from inequality in the quality of care (e.g. clinical processes and risk-adjusted outcomes). Resource inputs are the structural drivers of quality but do not provide a complete picture. However, although country-specific indicators of inequality in quality are available ${ }^{13}$, international comparisons are rare $^{12}$ because indicators of inequality in quality are typically based on country-specific administrative health datasets that are hard to harmonise and are not widely available in low- and middle-income countries.

Third, we define the ICL empirically without incorporating the concept of "market forces" or any other causal mechanism. This facilitates a dispassionate scientific approach to investigating different causal mechanisms and how they operate in different social, institutional and regulatory environments, including the market mechanisms emphasised by Tudor Hart (such as financial barriers for patients and labour market choices by doctors) but also mechanisms that can arise in both market and non-market settings (such as dysfunctional government, non-financial barriers and unequal costs and benefits of care).

Fourth, we distinguish complete and incomplete forms of the ICL. A complete ICL occurs when health care delivery is inversely related to social disadvantage in absolute terms (measured by resource input per capita). By contrast, an incomplete ICL occurs when health care delivery is not inversely related to social disadvantage in absolute terms but is in relative terms, after allowing for the additional needs of socially disadvantaged people. Or, paraphrasing Tudor-Hart, "the availability of health care is disproportionately related to the need for it in the population served". We call this incomplete form the "disproportionate care law" (DCL). 
The left-hand panel of Figure 1 illustrates the complete ICL, where socially disadvantaged populations receive less care than socially advantaged populations. The right-hand panel illustrates the DCL, where the absolute quantity of care is no longer inversely related to social disadvantage and may be positively related. However, the availability of health care is still lower in disadvantaged populations when we account for their additional need for health care.

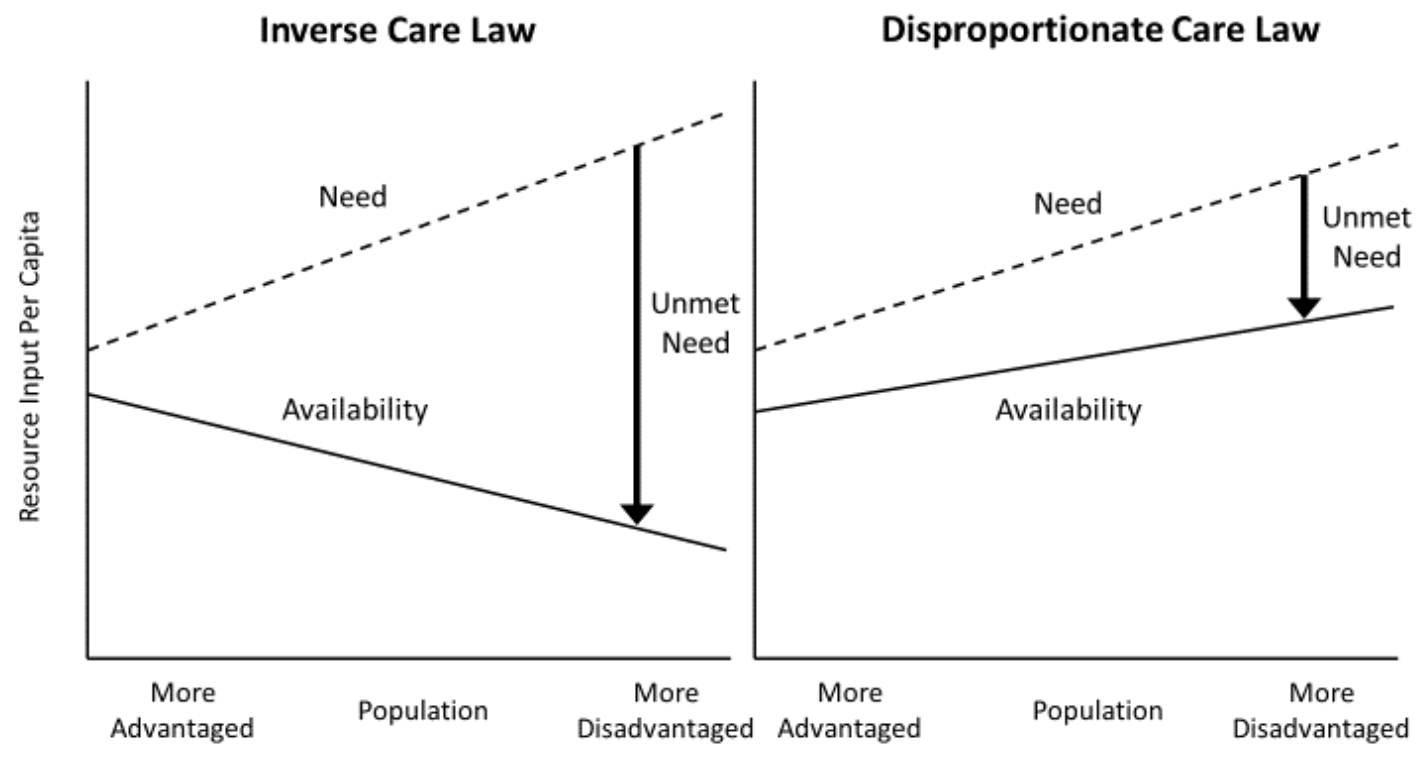

Figure 1: Inverse and disproportionate care laws

Resource input per capita can be measured, for example, as workforce, utilisation, or expenditure and stratified by age group.

Our re-formulated ICL then comes in two versions, each of which comprises two propositions - one about social inequality in health and one about social inequality in health care delivery:

1. Complete inverse care law - ICL

Social inequality in health: More socially disadvantaged people tend to have worse health than less socially disadvantaged people.

Complete social inequality in the quantity of health care delivery: More socially disadvantaged people tend to receive less health care than more socially advantaged people, and lower quality.

2. Disproportionate care law - DCL

Social inequality in health: More socially disadvantaged people tend to have worse health than less socially disadvantaged people.

Incomplete social inequality in the quantity of health care delivery: More socially disadvantaged people tend to receive more health care than more socially advantaged people but less as a proportion of need and lower quality.

The existence of social inequality in health is well-established: there are already numerous recent international reviews of the vast inter-disciplinary literature on the social determinants of health ${ }^{14-20}$ and the health determinants of social disadvantage ${ }^{21}$. In this article we therefore 
focus on social inequality in health care delivery. For reasons given above, we focus on quantity of health care in our international comparisons, but we acknowledge that quality is central to health care delivery and pay close attention to quality in our analysis of causes.

Empirically, it is easier to measure availability than need. Measuring need for health care is a conceptually challenging and data intensive task, requiring contestable value judgements as well as detailed data on morbidity and other need variables linked to data on resource use. ${ }^{22}$ Perhaps the most fundamental value judgement is whether the focus should be on need for health care that meets the highest current international standards of quality and effectiveness ("normative need") or need for health care that is cost-effective given current national health care resource constraints but may fall short of the highest standards ("comparative need"). ${ }^{23,24}$ Empirical studies almost always take the latter approach and estimate comparative need based on average resource use in the general population, as illustrated in Figure 2.

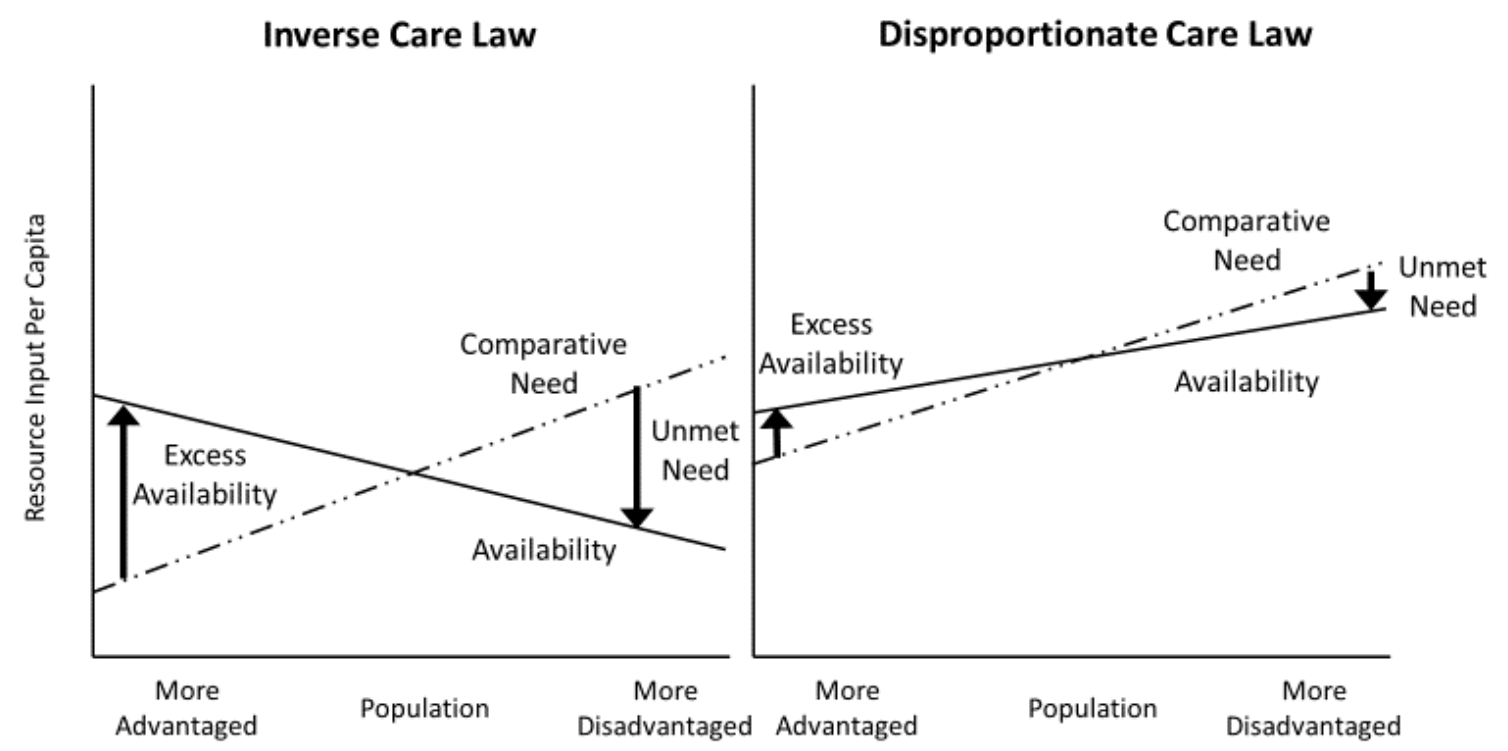

Figure 2: Inverse and disproportionate care laws based on comparative need

This approach rests on the contestable value judgement that, on average, people in the general population receive the care they need given current resource constraints. It also requires data on how needs vary between social groups. This is problematic because need variables are almost always incomplete - for example, information may be available on clinical diagnoses, but not severity, and information may not be available on other determinants of need such as health behaviour, living conditions, family support networks, travel distance to health care facilities and local labour market conditions. There are also problems of socially patterned morbidity reporting bias - for example, in low- and middle-income countries there is often a "reverse" social gradient in reported morbidity due to serious under-reporting of morbidity in socially disadvantaged populations with limited access to diagnostic care and low expectations. ${ }^{25}$ For all these reasons, it is easier to gather robust evidence demonstrating the existence of an ICL than a DCL.

Figure 3 illustrates the social patterning of ill-health and inpatient hospital utilisation in India and England - polar extreme cases with unusually large and small magnitudes of social inequality in health care delivery, respectively. India exhibits an ICL, with an inverse relationship between health care utilisation and ill-health. ${ }^{26}$ In England, however, inpatient 
hospital utilisation and ill-health are positively related (for both emergency and elective care $)^{27}$ and there is no ICL. Figure 3 does not tell us whether there is a DCL in England for inpatient care, since the amount of need cannot be inferred from life expectancy data alone, but there is evidence of a DCL in England using other indicators - especially for preventive care, primary care, community care and outpatient care but also for the utilisation, quality and risk-adjusted outcomes of specific elective inpatient services such as joint replacement and specific hospital procedures for cardiovascular disease and cancer. ${ }^{28-32}$

A
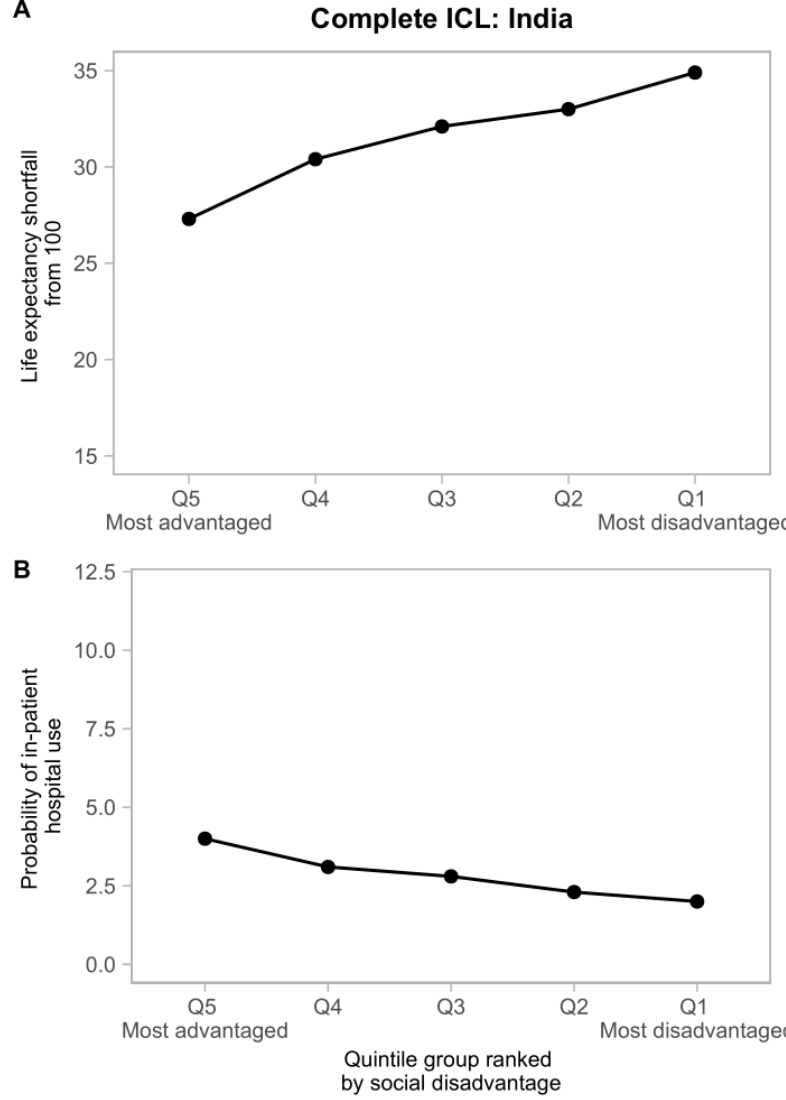

No complete ICL: England
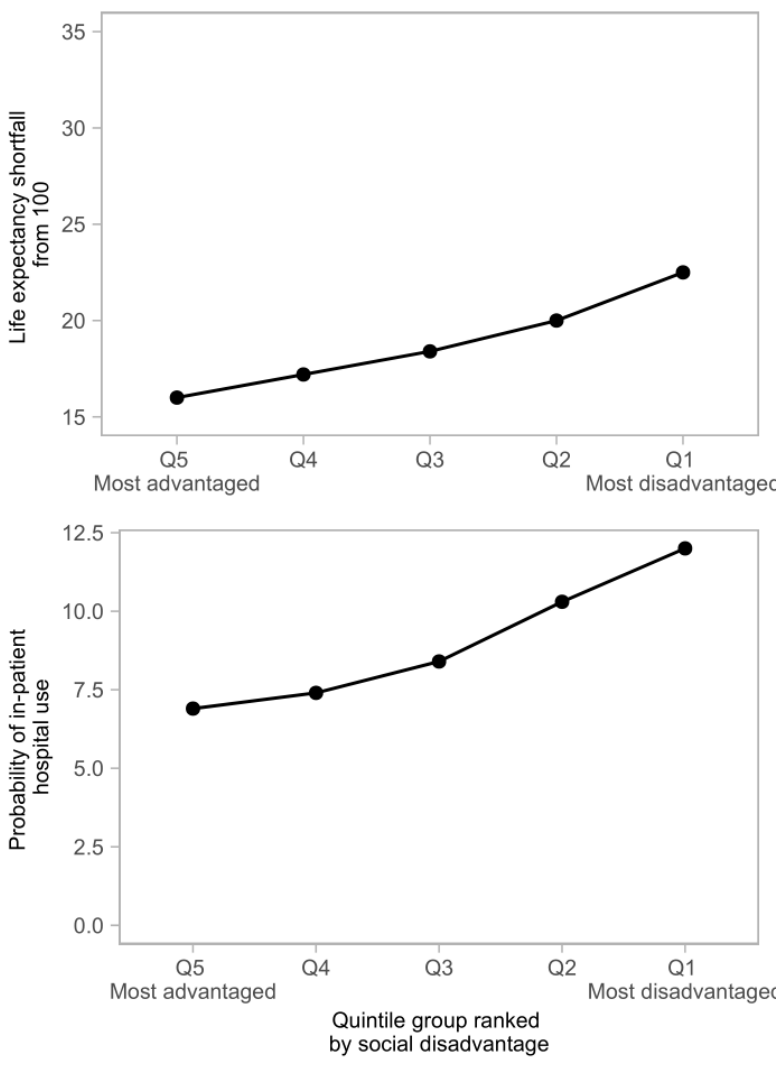

Figure 3: Complete and incomplete inverse care laws in India and England

Life expectancy shortfall (A) and probability of using inpatient hospital care (B) by socioeconomic quintile group in India and England. We take the inverse of life expectancy by calculating life expectancy shortfall, measured in both countries as 100 minus life expectancy at birth in $2011^{33,34}$. In both countries the probability of using inpatient hospital care in the past 12 months is measured using self-reported survey data from 2017/18 (National Sample Survey for India, Understanding Society for England) and includes both elective and emergency admissions ${ }^{35,36}$. In India this excludes childbirth. In England the socioeconomic quintile groups are based on neighbourhood deprivation in A and equivalised household annual income in B, whereas in India they are based on household asset wealth quintile in A and equivalised household monthly consumption in B.

This example also raises another conceptual challenge in need measurement, since the relatively high levels of inpatient hospital utilisation in more disadvantaged groups may partly reflect poor quality preventive, primary, community and outpatient care. The actual level of need for acute hospital care among disadvantaged populations may thus be higher than the counterfactual "ideal" level of need that could be achieved if inequalities in care quality were reduced for other forms of care. As we shall see, the magnitudes of ICLs and DCLs vary substantially between different kinds of care and tend to be larger for preventive services than for emergency and acute care services. 


\section{Cross-country comparisons of social inequality in health care delivery}

Social inequalities in health care delivery are ubiquitous and studies have documented ICLs and DCLs using diverse measures of health care quantity (e.g. doctors, utilisation, expenditure), quality (e.g. patient-reported experiences, clinical processes, risk-adjusted outcomes) and social disadvantage (e.g. income, occupational class, education, ethnicity and gender) at various levels of analysis including geographical (e.g. neighbourhood, city, region), organisational (e.g. family practice, hospital, insurance plan) and personal (e.g. household, family, individual $)^{30,37-40}$. There has also been useful front-line research on patient experience and medical experience in the tradition of Tudor Hart, which is especially useful in assessing and understanding inequality in the quality of care given the limitations of quantitative metrics. ${ }^{41-43}$

A complete ICL operates within almost all low- and middle-income countries, which usually have a high private expenditure share and/or highly fragmented systems of public funding with large urban-rural and employment-related differences in public coverage. In most cases the complete ICL remains when one restricts attention to publicly funded health care alone. ${ }^{4-}$ 46 Though there are exceptions among upper-middle income countries, including $\mathrm{Cuba}^{47}$, which introduced single payer health coverage in 1959, and countries that started introducing universal health coverage more recently such as Brazil (since 1988) ${ }^{48}$ and Thailand (since 2002) ${ }^{49}$. By contrast, a DCL operates in almost all high-income countries, which usually have integrated systems of universal coverage - either single payer or heavily regulated multipayer with limited divergence between health insurance plans - and a small $(<30 \%)$ private expenditure share. A partial exception is the US, which has a highly fragmented system of means-tested, age-related and employer-related public subsidies for health care and only provides something approaching universal coverage for the over $65 \mathrm{~s}^{50}$ Even in the US, however, there is only a complete ICL for ages 0 to 24 , whereby total health care expenditure per capita is higher among higher-income citizens ${ }^{51}$, though expenditure for disadvantaged groups is heavily skewed towards acute hospital and emergency services and there are DCLs by income and race at all ages and for all kinds of care based on numerous indicators ${ }^{52-54}$.

Country-specific studies cannot be used to make wide-ranging global comparisons of the magnitude of social inequality in health care delivery between countries, due to heterogeneity in variable definitions and inequality metrics, and incomplete reporting of underpinning data - i.e. detailed breakdowns by social group and unadjusted as well as adjusted findings usually precludes the re-construction of comparable inequality metrics. ${ }^{30}$

Nevertheless, some limited international comparisons of inequality in the quantity of care are possible among low- and middle-income countries and, separately, among high-income countries. International comparisons among low- and middle-income countries rely on household survey data from the Demographic and Health Survey and Multiple Indicator Cluster Survey programmes, which are limited to reproductive, maternal, newborn, and child health services and use a household wealth asset index to measure social disadvantage ${ }^{55,56}$. Using a composite index, these data reveal gaps between the richest and poorest ten percent of the population averaging $11.7 \%, 25.4 \%$ and $27.9 \%$ among upper-middle, lower-middle and low-income countries, respectively, with considerable variation ranging from nearly $0 \%$ 
(Thailand) to just over 50\% (Angola) (see Appendix A1) ${ }^{57}$. These data focus on utilisation of basic services needed by almost everyone within a specific target population (e.g. whether births are attended by a skilled midwife) without requiring adjustment for morbidity and need. However, they do not provide information about inequalities in later life or among men.

For high-income countries, cross-country household survey data on health care utilisation and morbidity are available for the full adult population. Information has recently been compiled by the OECD based on national health survey data for 33 EU and OECD countries between 2014 and 2017. ${ }^{58}$ These comparisons reveal differences in rates of health care use relative to need of around $0-20 \%$. For example, across countries, the probability of visiting a specialist in the past 12 months was on average 12 percentage points higher in the highest income quintile group compared with the lowest, after adjusting for age, gender, self-assessed health and activity limitation, with a significant gradient in almost all countries. Even larger gaps were found in relation to the uptake of specific preventive services needed by everyone within the target population, such as routine cervical screening, breast screening and dental check-ups. For example, the probability of cervical screening for women was on average 17 percentage points higher in the richest quintile group compared with the poorest, with statistically significant differences in 32 of the 33 countries. ${ }^{58-60}$ These inequalities in use of preventive services can be interpreted as ICLs, not merely DCLs. However, the average gap in the probability of any General Practitioner (GP) visit in the past 12 months was smaller, at only 5 percentage points, only significant for around half of the countries, and the number of repeat visits was higher in lower income groups. A recent international Commonwealth Fund survey finds even larger income differentials in self-reported unmet needs for health care in 11 high-income countries - for example, the average self-reported proportion of US citizens reporting they had skipped needed care due because of cost in the past year was 38\% with a statistically significant $23 \%$ differential between the richest and poorest income groups, compared with 10\% and 5\% (non-significant) in the UK, respectively. ${ }^{61}$ Overall this evidence shows that health care inequalities exist in all high-income countries but that the magnitude varies substantially between countries. However, caution is needed when interpreting country-level rankings within international health care inequality "league tables", since estimates that differ only by a few percentage points are subject not only to statistical uncertainty but also to potential cross-cultural survey response biases in how people in different countries and social groups understand and respond to questions about morbidity and unmet need. ${ }^{58}$

There is social inequality in health care between as well as within countries. Figure 4 illustrates the between-country ICL - poorer countries tend to suffer a higher burden of disease while providing fewer medical doctors per 10,000 population (see appendix figure A6 for the similarly strong association using risk-adjusted mortality as a quality indicator). 

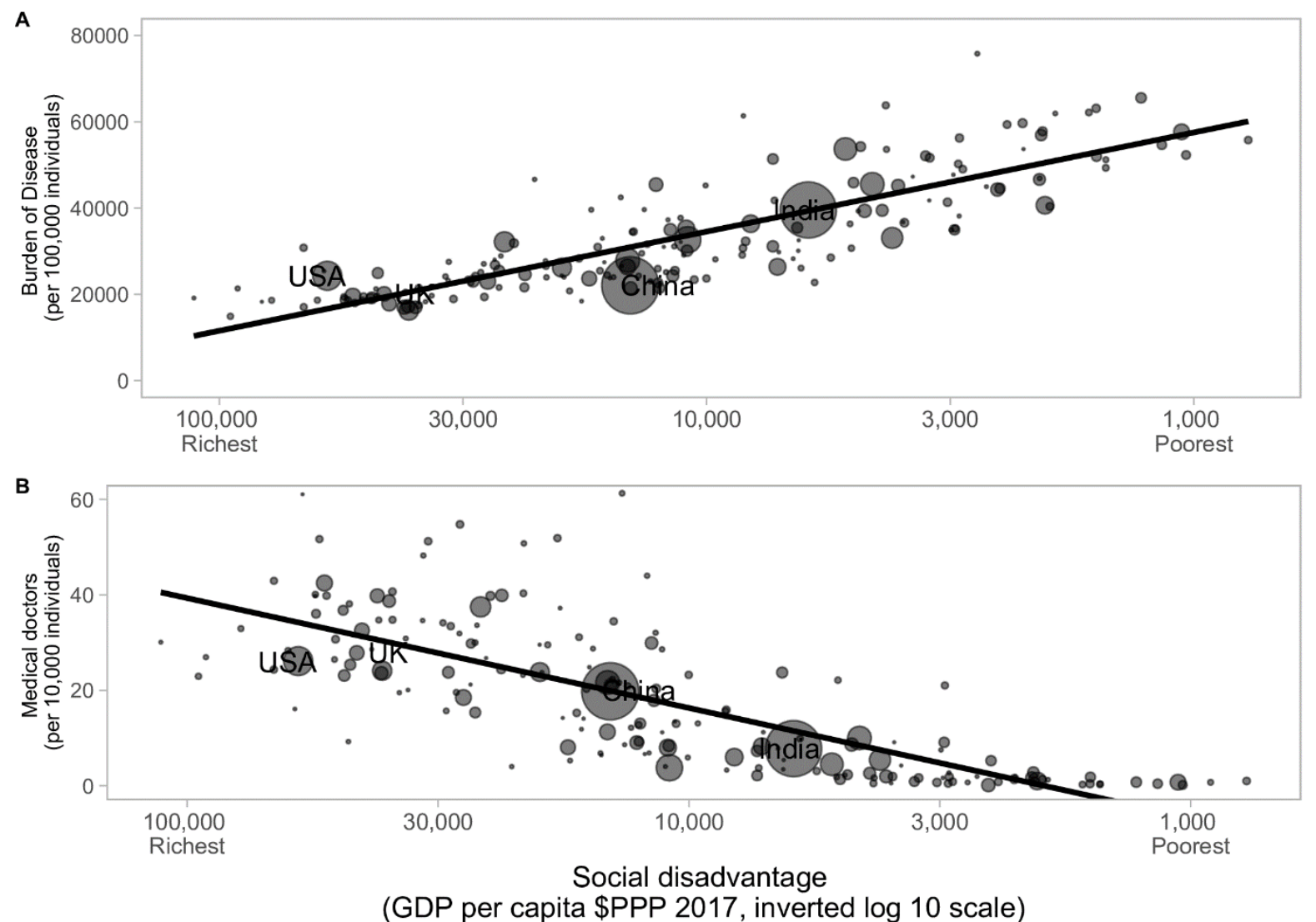

Figure 4: The global inverse care law-social inequality in health and health care between countries

Burden of Disease Per Capita (A) and Medical Doctors Per 10,000 Population (B) in 2016 for 180 countries inversely ranked by the log of national income in 2017. All data were extracted from the World Bank Database; the original source of burden of disease and healthcare access and quality data is Global Burden of Disease $2017^{62}$; the $\mathrm{x}$-axis is the log to base 10 of GDP per capita in constant 2010 US\$. The fitted lines are based on simple linear regressions without population weights, with slopes as follows: top (A) $-22,991$ (-25,285 to 20,696, 95\% CI) and R-squared 0.69; and bottom (B) 28.94 (26.71 to 31.18, 95\% CI) and R-squared 0.79 .

\section{The causes of social inequality in health care delivery}

Table 1 lists the main proximal causes of social inequality in health care delivery within countries. There are also distal "causes of the causes" - in particular, poor governance and inequalities in wealth, power, human capital and the conditions of daily life - which frustrate efforts to tackle social inequalities in health care. There is a clear cross-country correlation between the magnitude of health care inequality in low- and middle-income countries and the quality of governance as measured by the Worldwide Governance Indicators ${ }^{63}$ (see appendix Figure A2). ${ }^{64}$ However, there is no simple correlation between income inequality and health care inequality (see appendix figure A3) and relatively unequal countries like the UK and Thailand can achieve relatively low levels of health care inequality.

The first direct cause is financial barriers to health care - especially privately funded care. Financial barriers refer to the link between the health care received by an individual and the price paid by that individual or their family or employer - what economists refer to as "price rationing". The strength of this link is related to the total private share of health expenditure, especially the out-of-pocket share. However, it is not perfectly correlated, especially in highincome countries with heavily regulated insurance systems. For example, in Switzerland 
nearly $65 \%$ of care is privately funded but price rationing is weak because health insurance is mandatory with price and quality controls, means-tested subsidies and a risk adjustment mechanism to compensate insurers for covering people with pre-existing conditions. ${ }^{65,66}$

When price rationing is strong, individuals with greater ability to pay will tend to purchase more health care at any non-zero level of need. In India, for example, price rationing of health care via out-of-pocket payments is a major determinant of social inequality in health care. ${ }^{67}$ The impact of price rationing on social inequality in health care depends on income inequality rather than absolute levels of poverty. For example, India halved its absolute poverty rate during a period of rapid economic growth in the $1990 \mathrm{~s}$ and $2000 \mathrm{~s}$, ${ }^{68}$ yet social inequality in health care utilisation increased (see appendix figure A7). 
Table 1: Causes of social inequality in health care delivery

\begin{tabular}{|l|l|l|l|}
\hline $\begin{array}{l}\text { Social inequality in } \\
\text { ability to pay for } \\
\text { health care }\end{array}$ & $\begin{array}{l}\text { Richer individuals are } \\
\text { able to pay more for } \\
\text { health care and health } \\
\text { insurance }\end{array}$ & $\begin{array}{l}\text { Reographical Factors } \\
\text { are able to attract } \\
\text { more private } \\
\text { investment in health } \\
\text { care facilities }\end{array}$ & $\begin{array}{l}\text { Institutional Factors } \\
\text { richer patients are } \\
\text { able to charge higher } \\
\text { fees and attract larger } \\
\text { donations }\end{array}$ \\
\hline $\begin{array}{l}\text { Social inequality in } \\
\text { eligibility for } \\
\text { subsidised health care } \\
\text { insurance }\end{array}$ & $\begin{array}{l}\text { Ethnic minorities, } \\
\text { homeless people and } \\
\text { other vulnerable } \\
\text { groups may be less } \\
\text { eligible for public } \\
\text { subsidy }\end{array}$ & $\begin{array}{l}\text { Advantaged areas are } \\
\text { better able than } \\
\text { slums, rural areas and } \\
\text { ethnic enclaves to } \\
\text { attract public and } \\
\text { donor funding }\end{array}$ & $\begin{array}{l}\text { People in higher } \\
\text { status occupations } \\
\text { may be eligible for } \\
\text { better insurance plans } \\
\text { with larger public }\end{array}$ \\
subsidy
\end{tabular}

${ }^{1}$ The concept of "co-investment" encompasses various non-health care resource inputs invested by the patient and their carers to improve the effectiveness of health care resource inputs. Related concepts include "treatment burden" 69 "long-term care" and "self-care" but co-investment also includes broader investments in material and social living conditions that improve treatment compliance and recovery. 


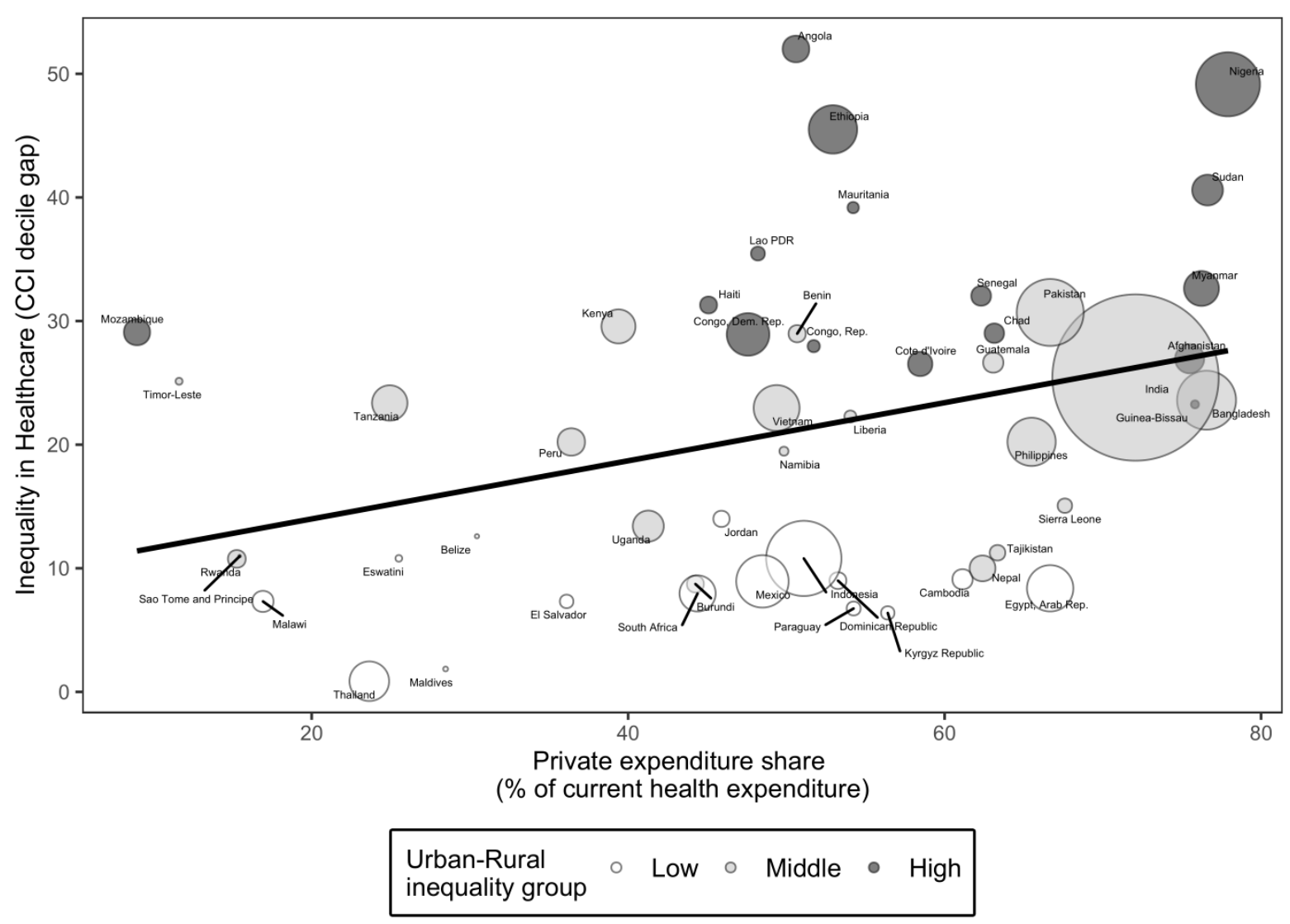

Figure 5: Health-care inequality and private health expenditure in low- and middle-income countries Percentage point difference in composite index of maternal and child health care utilisation ${ }^{56}$ between $^{2}$ highest and lowest decile group of household asset wealth versus private health care expenditure share ${ }^{70}$ in 62 low-income, lower-middle-income and upper-middle-income countries, split by low, middle and high tertile groups of urban-rural inequality in the same index. Source: WHO HEAT Too ${ }^{56}$ and WHO Global Health Expenditure database; full data in supplementary data appendix. The fitted line is based on a simple linear regression without population weights, with slope 0.24 (0.06 to $0.41,95 \% \mathrm{CI})$ and R-squared 0.11 . The composite coverage index is a weighted score reflecting receipt of eight reproductive, maternal, newborn and child health interventions along the continuum of care: demand for family planning satisfied (modern methods); antenatal care received (at least four visits); births attended by skilled health personnel; BCG immunization coverage among one-year-olds; measles immunization coverage among one-year-olds; DTP3 immunization coverage among one-year-olds; children aged less than five years with diarrhoea receiving oral rehydration therapy and continued feeding; and children aged less than five years with pneumonia symptoms taken to a health facility. ${ }^{71}$

Figure 5 shows the association between social inequality in health care delivery in low- and middle-income countries and the share of private health expenditure. The private expenditure share only "explains" $11 \%$ of the variation in health care inequality - less than the share "explained" by poor governance - illustrating our main finding that there are many other important causes of social inequality in health care.

A second important cause is fragmented public health insurance due to differential eligibility by ethnicity, caste, housing status, geography, occupational status and other dimensions of social disadvantage. Socially advantaged communities and the providers that serve them often have greater economic and political power, generating large geographical and provider- 
level inequalities in public and donor funding per capita for health care ${ }^{72}$. This is an especially powerful mechanism in many low- and middle-income countries, whereby public and donor funding tends to be concentrated on hospital care in urban areas rather than primary care in rural areas ${ }^{73}$. This occurs, for example, in Mozambique (top left of Figure 3), where most health care expenditure is funded by external donors ${ }^{74}$ and Nigeria (top right), which has a high share of private expenditure. ${ }^{75-77}$ The UK NHS successfully reduced geographical and institutional inequalities in hospital funding in the 1970s by introducing a geographical resource allocation formula, ${ }^{78,79}$ a policy innovation which has subsequently been adopted elsewhere ${ }^{80}$.

There are also important non-financial access barriers other than geographical location. Access to health care often requires the ability to navigate complex health care systems. Socially advantaged patients have greater health literacy, better digital access, fewer language problems, disabilities, and better social support from family and friends. For example, indigenous populations often face cultural and linguistic barriers to access in multiethnic societies, lending an additional dimension to stigma and discrimination. ${ }^{81}$ Access also requires taking time off work and family duties, which may be easier for socially advantaged individuals ${ }^{30}$, and effective communication and trust between patient and provider, which can advantage patients with similar cultural affiliations to providers ${ }^{82}$. In turn, practitioners' assessments of patient understanding, risk behaviour and capacity for self-management may be influenced by social status, ethnicity, gender and condition-related stigma, leading to implicit or explicit discrimination favouring more socially advantaged groups and more informed and effective decision-making ${ }^{83-87}$.

The third mechanism is unequal ability to co-invest in health care that improves health care effectiveness. Socially advantaged people are better able to comply with long-term treatment and lifestyle advice, facilitate communication and care co-ordination between providers, and provide themselves with a healthy recovery environment and rehabilitation services such as physiotherapy. ${ }^{30}$ The intergenerational transmission of social inequality via childhood development plays a large role in this mechanism. ${ }^{88-92}$ The human capital, social capital and cultural capital acquired during childhood has many benefits later in life - and one of them is a greater ability to co-invest in health care. Social inequality in the need for and cost of coinvestment can also operate at geographical levels - for example, disadvantaged people living in polluted areas are particularly vulnerable to the consequences of pollution including coping costs and poorer health outcomes. ${ }^{93}$ At the institutional level, well-funded providers with better facilities and access to support can transfer less of the effective cost of care onto patients.

The fourth mechanism is social inequality in the costs and benefits of health care delivery. The concentration of comorbidity, social problems and psychological distress in more deprived populations increases the cost of providing care ${ }^{27} 94$ which can result in quality being compromised or costs being shifted onto patients ${ }^{95}$. Additionally, medical students, who are disproportionately drawn from affluent urban communities ${ }^{96,97}$ tend to return to practice in similar communities to those from which they are drawn leaving rural and deprived communities struggling to recruit doctors. ${ }^{98-100}$ Experienced clinical staff are also lured away from the public to the private sectors by higher salaries and access to better specialist training and facilities ${ }^{101-103}$. Greater distance from health system infrastructures also reduces the availability of services ${ }^{104}$ and increases the costs of providing health care to 
more distant and deprived communities ${ }^{105}$. Finally, methods of quality assessment and healthcare provider reimbursement, including financial and reputational incentive schemes, often disadvantage institutions serving socially disadvantaged populations for whom targets are more challenging to achieve. ${ }^{106}$

The causes of social inequality in health care between countries have been less intensively studied. However, it is known that international labour market forces continue to attract welltrained doctors to high-income countries and away from low and middle-income countries ${ }^{103,107}$ and that international intellectual property regulations such as the WTO TRIPS agreement restrict affordable access to medicines in low- and middle-income countries. ${ }^{108}$

\section{Discussion}

A complete inverse care law (ICL) continues to operate in almost all low- and middle-income countries - i.e. health care workforce, utilisation and expenditure per capita are inversely related to social disadvantage - although its magnitude varies considerably. In contrast, an incomplete ICL, also of variable magnitude, operates in all upper-middle- and high-income countries with integrated systems of universal health coverage (UHC). In these countries, absolute health care expenditure is positively related to social disadvantage, especially but not only in relation to emergency hospital care. However, resource input as a proportion of need is still inversely related to social disadvantage, as is the quality of care, especially but not only in relation to preventive services, primary care workforce and outpatient hospital services - a "disproportionate care law" (DCL).

The main direct causes of a complete ICL are: (i) financial access barriers (out-of-pocket fees and insurance premiums) that link health care delivery with ability to pay; and (ii) public and donor funding mechanisms that link funding to the economic and political power of geographical areas and institutions rather than the needs of the populations served. A complete ICL can exist in countries which claim to be implementing UHC but in reality have fragmented systems of health insurance that that vary enormously by plan and region. ${ }^{109}$ In such settings, expansions of coverage that leave poor and rural communities behind can initially increase social inequality in health care (the "inverse equity hypothesis") ${ }^{9,110}$.

However, there are several other important mechanisms that cause social inequalities in health care delivery and generate substantial DCLs even in countries with integrated systems of UHC. These include inequalities in: the ability to seek health care; the ability to co-invest in health care; and in the costs and risks of health care delivery. Even if price rationing and geographical inequalities in public funding are virtually eliminated, social inequalities in health care remain. ${ }^{30}$ These additional factors can also give rise to "intervention-generated inequalities"111, whereby well-intentioned, cost-effective interventions increase health inequalities because socially advantaged individuals are better able to seek, co-invest and benefit from them. This can sometimes also generate difficult trade-offs between efficiency (improving total health) and equity (reducing health inequalities) ${ }^{112,113}$. For example, health care may be more cost-effective for socially advantaged individuals who are better able to seek and co-invest in care, who have with fewer social problems and risk factors that increase costs and worsen outcomes, and who do not live in disadvantaged areas that struggle to recruit doctors. ${ }^{6}$ 
For Tudor Hart, introducing integrated UHC was only the first step - UHC needed to be strengthened to remove the remaining social inequalities in health care. Since Tudor-Hart's original analysis, some limited progress has been made towards introducing universal health coverage in low-income and middle-income countries, reducing the magnitude of their complete ICLs ${ }^{114}$ and in some cases, such as Brazil ${ }^{48}$ and Thailand ${ }^{49}$, eliminating it. Furthermore, the general global trend has been towards a higher share of public expenditure on health care - even in the US, where the share of government expenditure is now about $58 \%$ (or $85 \%$ including compulsory private insurance). Overall, however, Tudor Hart would be disappointed at the limited global progress over the past 50 years in tackling the inverse care law in both its complete and incomplete forms. But he might not be surprised: he was well aware that large structural inequalities in wealth, power and poor governance make it hard for societies to develop and strengthen progressive health care funding systems whereby the rich and the healthy subsidise the poor and the sick. And he also emphasised the political role of excessively large and powerful private sector business interests in lobbying governments, capturing regulators and distorting national and international policymaking. There is hope for more rapid progress in the coming decades, however. Despite the disruption to global health care caused by the COVID-19 pandemic ${ }^{115}$ and the ongoing damage to economic growth and public finances, the large-scale collective responses may foster social solidarity and greater public awareness of inequalities in health and health care.

Tudor Hart was particularly concerned to reduce social inequalities in primary care, since these can play a substantial role in reducing wider inequalities in health from a population health perspective - especially but not only in countries without universal primary care. ${ }^{116-118}$ This also aligns well with a health economic perspective, according to which scarce resources should be prioritised towards highly cost-effective services - such as primary care, community care, preventive care and basic surgery - that deliver the largest returns to population health. ${ }^{119}$ However, strengthening primary care ${ }^{120}$ and improving the effectiveness and efficiency of all health services are necessary but not sufficient steps towards tackling inequalities in health. We also need better information about the health inequality impacts of health care decisions.

This will require a re-shaping of the health services research infrastructure to address equity as well as effectiveness and efficiency. ${ }^{121}$ Tudor Hart was an advocate of data gathering and an early adopter of clinical computing systems but may not have anticipated the role information would play in the $21^{\text {st }}$ century in perpetuating, rather than reducing, inequalities. Statistics are the eyes of the state, but the state has a blinkered view when it comes to the impacts of public health interventions. Public decision making still prioritises effectiveness and efficiency over equity, relying on analytical approaches that measure averages rather than social distributions ${ }^{122}$. Health inequality problems are often described ${ }^{13}$ without providing actionable intelligence about solutions, and health technologies, programmes and policies are still routinely evaluated without any serious attempt to quantify their impacts on social inequalities in health and health care. ${ }^{123}$ All too often, health technology assessments use inflated value-for-money thresholds ${ }^{124,125}$ and pay no attention to the social distribution of opportunity costs, shifting attention away from reducing health care inequality.

Resource constrained decision makers on the path to UHC may face hard choices between covering more people, covering more services, reducing user fees, and funding programmes to tackle non-financial barriers to access such as discrimination and digital divides. ${ }^{126}$ 
Different choices will have different impacts on effectiveness, efficiency and equity. Given resource constraints there are also broader social choices about how much to spend on health care versus other social programmes - education, employment, social protection and so on that might be more cost-effective ways of improving health and reducing health inequalities. ${ }^{127}$

The inverse care law thus has radical, transformative research implications both for health services researchers - who need to pay more attention to equity - and for health equity researchers - who need to pay more attention to policy trade-offs. By bringing the two perspectives together, health care decisions can be informed by evidence about their impacts on equity as well as their effectiveness and efficiency. Methods of distributional costeffectiveness analysis are now available to make equity a measurable endpoint of health technology and health policy assessment. ${ }^{128,129}$ If they are serious about tackling health inequalities then decision makers should start using these methods and routinely subject health technologies and policies to distributional analysis of their health equity impacts. 


\section{Acknowledgements}

Richard Cookson, Tim Doran and Fiorella Parra Mujica are supported by the Wellcome Trust (Grant No. 205427/Z/16/Z).

For helpful comments we would like to thank Mark Ashworth, Rama Baru, Chris Bentley, Callum Brindley, Kevin Fiscella, Robert Fleetcroft, John Ford, Peter Goldblatt, Hugh Gravelle, Davidson Gwatkin, Elaine Kelly, Julian Le Grand, Ajay Mahal, Owen O'Donnell, Trevor Sheldon, Peter Smith, Cesar Victora, Elizabeth Walton and Margaret Whitehead.

We take full responsibility for all errors and opinions expressed in this publication and exonerate the Wellcome Trust and all those who provided comments.

\section{Role of the funding source}

The Wellcome Trust had no role in the manuscript writing or decision to submit. All authors had full access to the full data in the study and accept responsibility to submit for publication.

\section{Authors' contributions}

All authors contributed to the study design, literature search, data interpretation and writing; $\mathrm{RC}$ co-ordinated the study team and led the writing up; FP collected and analysed the data and created the figures; IG provided additional previously unpublished data on health care inequality in India from the National Sample Survey Round 75; FP and RC accessed and verified the underlying data. 


\section{References}

1 Tudor Hart J. The Inverse Care Law. Lancet 1971; 297: 405-12.

2 Marmot M. An inverse care law for our time. Br Med J 2018; 362. DOI:10.1136/bmj.k3216.

3 Warren P. Julian Tudor Hart: visionary general practitioner who introduced the concept of the inverse care law. Br Med J 2018; 362. DOI:10.1136/bmj.k3052.

4 Cooper K. A Review of the Literature: Does the Inverse Care Law Still Apply Today? Social. Heal. Assoc. 2010. https://www.sochealth.co.uk/national-health-service/publichealth-and-wellbeing/poverty-and-inequality/the-inverse-care-law/a-review-of-theliterature-does-the-inverse-care-law-still-apply-today/ (accessed Nov 22, 2020). Le Grand J. The Strategy of Equality. London: George Allen and Unwin, 1982.

$6 \quad$ Watt G. The Inverse Care Law Today. Lancet 2002; 360: 252-4.

7 Watt G. The inverse care law revisited: A continuing blot on the record of the National Health Service. Br. J. Gen. Pract. 2018; 68: 562-3.

8 Sengupta A. Universal Health Coverage: Beyond rhetoric. Munic. Serv. Proj. 2013; : 25.

9 Victora CG, Joseph G, Silva ICM, et al. The inverse equity hypothesis: Analyses of institutional deliveries in 286 national surveys. Am. J. Public Health. 2018; 108: 464 71.

10 Victora CG, Vaughan JP, Barros FC, Silva AC, Tomasi E. Explaining trends in inequities: Evidence from Brazilian child health studies. Lancet 2000; 356: 1093-8.

11 Krieger N, Chen JT, Waterman PD, et al. The inverse hazard law: Blood pressure, sexual harassment, racial discrimination, workplace abuse and occupational exposures in US low-income black, white and Latino workers. Soc Sci Med 2008; 67: 1970-81.

12 Arsenault C, Jordan K, Lee D, et al. Equity in antenatal care quality: an analysis of 91 national household surveys. Lancet Glob Heal 2018; 6: e1186-95.

13 Cookson R, Asaria M, Ali S, Shaw R, Doran T, Goldblatt P. Health equity monitoring for healthcare quality assurance. Soc Sci Med 2018; 198.

DOI:10.1016/j.socscimed.2018.01.004.

14 Marmot M, Friel S, Bell R, Houweling TA, Taylor S. Closing the gap in a generation: health equity through action on the social determinants of health. Lancet 2008; $\mathbf{3 7 2}$ : 1661-9.

15 Marmot M, Allen J, Bell R, Bloomer E, Goldblatt P. WHO European review of social determinants of health and the health divide. Lancet 2012; 380: 1011-29.

16 Pan American Health Organization. Just Societies: Health Equity and Dignified Lives. Report of the Commission of the Pan American Health Organization on Equity and Health Inequalities in the Americas. Washington, D.C., 2019 https://iris.paho.org/handle/10665.2/51571 (accessed Nov 7, 2020).

17 Adler NE, Stewart J. Preface to The Biology of Disadvantage: Socioeconomic Status and Health. Ann. N. Y. Acad. Sci. 2010; 1186: 1-4.

18 Cash-Gibson L, Rojas-Gualdrón DF, Pericàs JM, Benach J. Inequalities in global health inequalities research: A 50-year bibliometric analysis (1966-2015). PLoS One 2018; 13: 1-22.

19 Collyer TA, Smith KE. An atlas of health inequalities and health disparities research: "How is this all getting done in silos, and why?" Soc Sci Med 2020; 264: 113330.

20 Blas E, Kurup S, editors. Equity, social determinants and public health programmes. World Health Organization, 2010.

21 O'Donnell O, Van Doorslaer E, Van Ourti T. Health and inequality. In: Handbook of Income Distribution. Elsevier B.V., 2015: 1419-533. 
22 O'Donnell O, Doorslaer E Van. Analyzing Health Equity Using Household Survey Data,. Washington. 2008 DOI:10.2471/BLT.08.052357.

23 Culyer AJ. Need: the idea won't do but we still need it. In: Cookson R, Claxton K, eds. The Humble Economist: Tony Culyer on Health, Health Care and Social Decision Making. University of York and Office of Health Economics, 2012: 133-52.

24 Bradshaw, Jonathan. Taxonomy of social need. In: McLachlan G, ed. Problems and progress in medical care: essays on current research: 7th series. London: Oxford University Press, 1972: 71-82.

25 Sen A. Health: perception versus observation. Self reported morbidity has severe limitations and can be extremely misleading. BMJ 2002; 324: 860-1.

26 Banerjee S, Roy Chowdhury I. Inequities in curative health-care utilization among the adult population (20-59 years) in India: A comparative analysis of NSS 71st (2014) and 75th (2017-18) rounds. PLoS One 2020; 15: e0241994.

27 Asaria M, Doran T, Cookson R. The costs of inequality: Whole-population modelling study of lifetime inpatient hospital costs in the English National Health Service by level of neighbourhood deprivation. J Epidemiol Community Health 2016. DOI:10.1136/jech-2016-207447.

28 Delgadillo J, Asaria M, Ali S, Gilbody S. On poverty, politics and psychology: the socioeconomic gradient of mental healthcare utilisation and outcomes. Br J Psychiatry 2015; published online Nov. DOI:10.1192/bjp.bp.115.171017.

29 STOYE G, ZARANKO B, SHIPLEY M, MCKEE M, BRUNNER EJ. Educational Inequalities in Hospital Use Among Older Adults in England, 2004-2015. Milbank $Q$ 2020; : 1468-0009.12479.

30 Cookson R, Propper C, Asaria M, Raine R. Socio-Economic Inequalities in Health Care in England. 2016 DOI:10.1111/1475-5890.12109.

31 Fisher R, Dunn P, Gershlick B, Asaria M, Thorlby R. Level or not? 2020 DOI:10.37829/HF-2020-RC13.

32 Dixon J, King D, Matosevic T, Clark M, Knapp M. Equity in the Provision of Palliative Care in the UK : Review of Evidence. 2015

https://www.mariecurie.org.uk/globalassets/media/documents/policy/campaigns/equity -palliative-care-uk-report-full-lse.pdf.

33 Love-Koh J, Asaria M, Cookson R, Griffin S. The Social Distribution of Health: Estimating Quality-Adjusted Life Expectancy in England. Value Heal 2015; 18: 65562.

34 Asaria M, Mazumdar S, Chowdhury S, Mazumdar P, Mukhopadhyay A, Gupta I. Socioeconomic inequality in life expectancy in India. BMJ Glob Heal 2019; 4. DOI:10.1136/bmjgh-2019-001445.

35 University of Essex, Institute for Social and Economic Research, NatCen Social Research, Kantar Public. Understanding Society: Waves 1-9, 2009-2018 and Harmonised BHPS: Waves 1-18, 1991-2009. [data collection] 12th Edition. UK Data Serv. SN 6614. 2019. http://doi.org/10.5255/UKDA-SN-6614-13.

36 Government of India. Key indicators of social consumption in India: Health. Natl Sample Surv Organ 2019; : 1-127.

37 Bago d'Uva T, Jones AM, van Doorslaer E. Measurement of horizontal inequity in health care utilisation using European panel data. J Health Econ 2009; 28: 280-9.

38 Wagstaff A, Bredenkamp C, Buisman LR. Progress on global health goals: Are the poor being left behind? World Bank Res Obs 2014; 29: 137-62.

39 Galea S, Abdalla SM. COVID-19 Pandemic, Unemployment, and Civil Unrest: Underlying Deep Racial and Socioeconomic Divides. JAMA - J. Am. Med. Assoc. 2020; 324: 227-8. 
40 WHO, The World Bank. Tracking Universal Health Coverage: 2017 Global Monitoring Report. 2017

https://apps.who.int/iris/bitstream/handle/10665/259817/9789241513555-

eng.pdf;jsessionid=C29E21005A5692511BE2B70BD2D3C941?se.

41 Watt G. GPs at the deep end. Br. J. Gen. Pract. 2011; 61: 66-7.

42 Sturgiss, Elizabeth; Tait, Peter; Douglas, Kirsty; Chew, Joo-Inn; Baglow, Susan; Watt G. GPs at the deep end: 'Identifying and addressing social disadvantage wherever it lies'. Aust J Gen Pract 2019; 48.

https://search.informit.com.au/documentSummary; $\mathrm{dn}=729095236713033 ;$ res=IELHE A (accessed Jan 7, 2021).

43 Mathers CD. History of global burden of disease assessment at the World Health Organization. Arch Public Heal 2020; 78: 1-13.

44 Bowser D, Patenaude B, Bhawalkar M, Duran D, Berman P. Benefit incidence analysis in public health facilities in India: Utilization and benefits at the national and state levels. Int J Equity Health 2019; 18: 13.

45 McIntyre D, Ataguba JE. How to do (or not to do) ... a benefit incidence analysis. Health Policy Plan 2010; 26: 174-82.

46 Asante A, Price J, Hayen A, Jan S, Wiseman V. Equity in Health Care Financing in Low- and Middle-Income Countries: A Systematic Review of Evidence from Studies Using Benefit and Financing Incidence Analyses. PLoS One 2016; 11: 1-20.

47 Atun R, De Andrade LOM, Almeida G, et al. Health-system reform and universal health coverage in Latin America. Lancet. 2015; 385: 1230-47.

48 Barbosa EC, Cookson R. Multiple inequity in health care: An example from Brazil. Soc Sci Med 2019; 228. DOI:10.1016/j.socscimed.2019.02.034.

49 Tangcharoensathien V, Patcharanarumol W, Kulthanmanusorn A, Saengruang N, Kosiyaporn H. The Political Economy of UHC Reform in Thailand: Lessons for Lowand Middle-Income Countries. Heal Syst Reform 2019; 5: 195-208.

50 Tikkanen R, Osborn R, Mossialos E, Djordjevic A, Wharton GA. United States. Int. Heal. Care Syst. Profiles. 2020. https://www.commonwealthfund.org/internationalhealth-policy-center/countries/united-states (accessed Nov 22, 2020).

51 French E, Kelly E. Medical Spending around the Developed World. Fisc Stud 2016; 37: $327-44$.

52 Fiscella K, Franks P, Gold MR, Clancy CM. Inequality in quality: addressing socioeconomic, racial, and ethnic disparities in health care. JAMA 2000. DOI:10.1001/jama.283.19.2579.

53 Fiscella K, Sanders MR. Racial and Ethnic Disparities in the Quality of Health Care. Annu Rev Public Health 2016; 37: 375-94.

54 Agency for Healthcare Research and Quality, Rockville M. 2018 National Healthcare Quality and Disparities Report. 2020.

https://www.ahrq.gov/research/findings/nhqrdr/nhqdr18/index.html.

55 Gwatkin DR. Trends in health inequalities in developing countries. Lancet Glob. Heal. 2017; 5: e371-2.

56 Geneva: World Health Organization [WHO]. Health Equity Assessment Toolkit (HEAT): Software for exploring and comparing health inequalities in countries. Builtin database edition. Version 4.0. 2020. https://portal.who.int/heat/ (accessed Nov 6, 2020).

57 Victora CG, Barros AJD, França GVA, da Silva ICM, Carvajal-Velez L, Amouzou A. The contribution of poor and rural populations to national trends in reproductive, maternal, newborn, and child health coverage: analyses of cross-sectional surveys from 64 countries. Lancet Glob Heal 2017; 5: e402-7. 
DOI:https://doi.org/https://doi.org/10.1787/3c8385d0-en.

59 McKinnon B, Harper S, Moore S. Decomposing income-related inequality in cervical screening in 67 countries. Int J Public Health 2011; 56: 139-52.

60 Carrieri V, Wuebker A. Assessing inequalities in preventive care use in Europe. Health Policy (New York) 2013; 113: 247-57.

61 Doty BMM, Tikkanen RS, Fitzgerald M, Fields K, Williams II RD. Income-Related Inequality In Affordability And Access To Primary Care In Eleven High- Income Countries. Health Aff 2021; 40: 1-8.

62 Institute for Health Metrics and Evaluation (IHME). Global Burden of Disease Study 2017 (GBD 2017) Results. 2015. http://ghdx.healthdata.org/gbd-results-tool (accessed Nov 6, 2020).

63 World Bank. Worldwide Governance Indicators. 2019. https://info.worldbank.org/governance/wgi/ (accessed Jan 8, 2021).

64 Wagstaff A, Bilger M, Buisman L, Bredenkamp C. Who Benefits from Government Health Spending and Why? A Global Assessment. 2014; published online Sept 1. https://papers.ssrn.com/abstract=2500586 (accessed Nov 24, 2020).

65 Reinhardt UE. The Swiss Health SystemRegulated Competition Without Managed Care. JAMA 2004; 292: 1227-31.

66 Tikkanen R, Osborn R, Mossialos E, Djordjevic A, Wharton GA. Switzerland. Int. Heal. Care Syst. Profiles. 2020. https://www.commonwealthfund.org/internationalhealth-policy-center/countries/switzerland (accessed Nov 22, 2020).

67 Dwivedi R, Pradhan J. Does equity in healthcare spending exist among Indian states? Explaining regional variations from national sample survey data. Int. J. Equity Health. 2017; 16: 1-12.

68 Himanshu. Widening Gaps: India Inequality report 2018. Oxfam India 2018. https://www.oxfamindia.org/sites/default/files/WideningGaps_IndiaInequalityReport2 018.pdf.

69 Dobler CC, Harb N, Maguire CA, Armour CL, Coleman C, Murad MH. Treatment burden should be included in clinical practice guidelines. BMJ 2018; 363.

DOI:10.1136/bmj.k4065.

70 World Health Organization [WHO]. Global Health Expenditure Database. 2020. http://apps.who.int/nha/database/Home/Index/en. (accessed Nov 6, 2020).

71 Wehrmeister FC, Barros AJD, Hosseinpoor AR, Boerma T, Victora CG. Measuring universal health coverage in reproductive, maternal, newborn and child health: An update of the composite coverage index. PLoS One 2020; 15: 1-10.

72 Singh N. Decentralization And Public Delivery Of Health Care Services In India. Health Aff 2008; 27: 991-1001.

73 Joseph G, da Silva ICM, Barros AJD, Victora CG. Socioeconomic inequalities in access to skilled birth attendance among urban and rural women in low-income and middle-income countries. BMJ Glob Heal 2018; 3. DOI:10.1136/bmjgh-2018-000898.

74 Pfeiffer J, Chapman RR. NGOs, austerity, and universal health coverage in Mozambique. Global Health 2019; 15: 0.

75 Nwosu CO, Ataguba JE. Socioeconomic inequalities in maternal health service utilisation: a case of antenatal care in Nigeria using a decomposition approach. BMC Public Health 2019; 19: 1493.

76 Adeyanju O, Tubeuf S, Ensor T. Socio-economic inequalities in access to maternal and child healthcare in Nigeria: Changes over time and decomposition analysis. 2017 DOI:10.1093/heapol/czx049.

77 Faye CM, Wehrmeister FC, Melesse DY, et al. Large and persistent subnational 
inequalities in reproductive, maternal, newborn and child health intervention coverage in sub-Saharan Africa. BMJ Glob Heal 2020; 5: e002232-e002232.

78 Smith PC. Formula Funding of Public Services: An Economic Analysis. Oxford Rev Econ Policy 2003; 19: 301-22.

79 Smith P. Resource allocation and purchasing in the health sector: the English experience. Bull World Health Organ 2008; 86: 884-8.

80 McGuire F, Revill P, Twea P, Mohan S, Manthalu G, Smith PC. Allocating resources to support universal health coverage: Development of a geographical funding formula in Malawi. BMJ Glob Heal 2020; 5. DOI:10.1136/bmjgh-2020-002763.

81 Tobasia-Hege C, Pinart M, Madeira S, et al. Disrespect and abuse during childbirth and abortion in Latin America: systematic review and meta-analysis. Rev Panam SALUD PUBLICA-PAN Am J PUBLIC Heal 2019; 43. DOI:10.26633/RPSP.2019.36. Berkman ND, Sheridan SL, Donahue KE, et al. Health literacy interventions and outcomes: an updated systematic review. Evid Rep Technol Assess (Full Rep) 2011; : $1-941$.

83 Balsa AI, McGuire TG, Meredith LS. Testing for statistical discrimination in health care. Health Serv. Res. 2005; 40: 227-52.

84 Lewis TT, Cogburn CD, Williams DR. Self-Reported Experiences of Discrimination and Health: Scientific Advances, Ongoing Controversies, and Emerging Issues. Annu Rev Clin Psychol 2015; 11: 407-40.

85 Rivenbark JG, Ichou M. Discrimination in healthcare as a barrier to care: experiences of socially disadvantaged populations in France from a nationally representative survey. BMC Public Health 2020; 20: 31.

86 Durand M-A, Carpenter L, Dolan H, et al. Do interventions designed to support shared decision-making reduce health inequalities? A systematic review and meta-analysis. PLoS One 2014; 9: e94670.

87 Ben J, Cormack D, Harris R, Paradies Y. Racism and health service utilisation: A systematic review and meta-analysis. PLoS One 2017; 12: e0189900.

88 Heckman JJ. The economics, technology, and neuroscience of human capability formation. Proc Natl Acad Sci U S A 2007; 104: 13250-5.

89 Almond D, Currie J, Duque V. Childhood Circumstances and Adult Outcomes: Act II. J Econ Lit 2018; 56: 1360-446.

90 Nelson CA, Bhutta ZA, Burke Harris N, Danese A, Samara M. Adversity in childhood is linked to mental and physical health throughout life. BMJ 2020; 371: $\mathrm{m} 3048$.

91 Braveman P, Barclay C. Health disparities beginning in childhood: a life-course perspective. Pediatrics 2009; 124 Suppl: S163-75.

92 Conti G, Mason G, Poupakis S. Developmental Origins of Health Inequality. 2019. DOI:10.1093/acrefore/9780190625979.013.4.

93 Gupta S, Das S, Murty MN. Quantifying Air Pollution Vulnerability and its Distributional Consequences. Ecol Econ Soc INSEE J 2019; 2: 93-125.

94 McPhail SM. Multimorbidity in chronic disease: Impact on health care resources and costs. Risk Manag Healthc Policy 2016; 9: 143-56.

95 Sum G, Hone T, Atun R, et al. Multimorbidity and out-of-pocket expenditure on medicines: A systematic review. BMJ Glob Heal 2018; 3: 1-12.

96 Steven K, Dowell J, Jackson C, Guthrie B. Fair access to medicine? Retrospective analysis of UK medical schools application data 2009-2012 using three measures of socioeconomic status. BMC Med Educ 2016; 16: 1-10.

97 Dowell J, Norbury M, Steven K, Guthrie B. Widening access to medicine may improve general practitioner recruitment in deprived and rural communities: Survey of GP origins and current place of work Career choice, professional education and 
development. BMC Med Educ 2015; 15: 1-7.

98 Wilson NW, Couper ID, De Vries E, Reid S, Fish T, Marais BJ. A critical review of interventions to redress the inequitable distribution of healthcare professionals to rural and remote areas. Rural Remote Health 2009; 9: 1060.

99 Dolea C, Stormont L, Braichet JM. Evaluated strategies to increase attraction and retention of health workers in remote and rural areas. Bull World Health Organ 2010; 88: $379-85$.

100 Verma P, Ford JA, Stuart A, Howe A, Everington S, Steel N. A systematic review of strategies to recruit and retain primary care doctors. BMC Health Serv Res 2016; 16. DOI:10.1186/s12913-016-1370-1.

101 Sherr K, Mussa A, Chilundo B, et al. Brain drain and health workforce distortions in Mozambique. PLoS One 2012; 7. DOI:10.1371/journal.pone.0035840.

102 Basu S, Andrews J, Kishore S, Panjabi R, Stuckler D. Comparative performance of private and public healthcare systems in low- and middle-income countries: A systematic review. PLoS Med 2012; 9: 19.

103 Mullan F. Doctors for the world: Indian physician emigration. Health Aff 2006; 25: 380-93.

104 Huot S, Ho H, Ko A, et al. Identifying barriers to healthcare delivery and access in the Circumpolar North: important insights for health professionals. Int J Circumpolar Health 2019; 78: 1571385.

105 Bertolini P, Montanari M, Peragine V. Poverty and Social exclusion in rural areas. Eur Comm 2008.

106 Doran T, Maurer KA, Ryan AM. Impact of Provider Incentives on Quality and Value of Health Care. Annu Rev Public Health 2017; 38: 449-65.

107 Mullan F. The Metrics of the Physician Brain Drain. N Engl J Med 2005; 353: 1810-8.

108 Smith RD, Correa C, Oh C. Trade, TRIPS, and pharmaceuticals. Lancet 2009; 373: 684-91.

109 Shroff ZC, Marten R, Ghaffar A, et al. On the path to Universal Health Coverage: aligning ongoing health systems reforms in India. BMJ Glob Heal 2020; 5: 3801.

110 Gwatkin DR, Ergo A. Universal health coverage: Friend or foe of health equity? Lancet. 2011; 377: 2160-1.

111 Lorenc T, Petticrew M, Welch V, Tugwell P. What types of interventions generate inequalities? Evidence from systematic reviews. J Epidemiol Community Heal 2012; : 190-3.

112 Williams AH, Cookson RA. Equity-efficiency trade-offs in health technology assessment. Int J Technol Assess Health Care 2006; 22: 1-9.

113 FRYATT R (BOB). Reaching the Poor with Health, Nutrition and Population Services: What Works, What Doesn't, and Why. Davidson R Gwatkin, Adam Wagstaff and Abdo S Yazbeck (eds). USA: The World Bank, pp. 300, \$30 (Paperback), 2005, ISBN: 0821359614. Int J Epidemiol 2006; 35: 1109-10.

114 Boerma T, Eozenou P, Evans D, Evans T, Kieny M-P, Wagstaff A. Monitoring Progress towards Universal Health Coverage at Country and Global Levels. PLoS Med 2014; 11: e1001731.

115 United Nations. The Sustainable Development Goals Report. 2020 mozextension://6022279e-72e4-41e4-ad23-8ab7d6a42257/enhancedreader.html?openApp\&pdf=https $\% 3 \mathrm{~A} \% 2 \mathrm{~F} \% 2$ Funstats.un.org\% $\%$ Fsdgs $\% 2$ Freport $\% 2 \mathrm{~F}$ 2020\%2FThe-Sustainable-Development-Goals-Report-2020.pdf (accessed Nov 30, 2020).

116 Sheldon T. Vigorous implementation of effective care can reduce inequalities in health. J Heal Serv Res Policy 2011; 16: 118-20. 
117 Barr B, Bambra C, Whitehead M. The impact of NHS resource allocation policy on health inequalities in England 2001-11: longitudinal ecological study. BMJ 2014; 348 : g3231.

118 Starfield B, Shi L, Macinko J. Contribution of primary care to health systems and health. Milbank $Q$ 2005; 83: 457-502.

119 Haines A, Sanders D, Lehmann U, et al. Achieving child survival goals: potential contribution of community health workers. Lancet 2007; 369: 2121-31.

120 Walley J, Lawn JE, Tinker A, et al. Primary health care: making Alma-Ata a reality. Lancet. 2008; 372: 1001-7.

121 Cookson R, Robson M, Skarda I, Doran T. Equity-informative methods of health services research. J Health Organ Manag.

122 Doran T, Cookson R. Re-engineering Health Policy Research to Measure Equity Impacts. In: Evans J, Ruane S, Southall H, eds. Data in Society: Challenging Statistics in an Age of Globalisation. Bristol: Policy Press, 2019.

123 Horton R. Offline: The error of our health technology assessment ways. Lancet. 2013; 382: 1318.

124 Leech AA, Kim DD, Cohen JT, Neumann PJ. Use and Misuse of Cost-Effectiveness Analysis Thresholds in Low- and Middle-Income Countries: Trends in Cost-perDALY Studies. Value Heal 2018; 21: 759-61.

125 Woods B, Revill P, Sculpher M, Claxton K. Country-Level Cost-Effectiveness Thresholds: Initial Estimates and the Need for Further Research. Value Heal 2016; 19 : 929-35.

126 World Health Organization. Making fair choices on the path to universal health coverage: final report of the WHO consultative group on equity and universal health coverage. World Health Organization, 2014 https://apps.who.int/iris/handle/10665/112671.

127 Asthana S, Gibson A, Halliday J. The medicalisation of health inequalities and the English NHS: the role of resource allocation. Heal Econ Policy Law 2012; : 1-17.

128 Cookson R, Griffin S, Norheim OF, Culyer AJ. Distributional Cost-Effectiveness Analysis: Quantifying Health Equity Impacts and Trade-Offs. Oxford University Press, 2020.

129 Cookson R, Griffin S, Norheim OF, Culyer AJ, Chalkidou K. Distributional CostEffectiveness Analysis Comes of Age. Value Heal 2021; 24: 118-20. 